\title{
Comunidades costeras del noroeste mexicano haciendo ciencia
}

\author{
Northwest Coastal Communities in Mexico Doing Science
}

\author{
Victoria Jiménez Esquivel \\ CENTRO PARA LA BIODIVERSIDAD MARINA Y LA CONSERVACIÓN AC, \\ victoria.jimenez@gocmarineprogram.org
}

\section{Catalina López-Sagástegui}

UCMEXUS, UNIVERSITY OF CALIFORNIA, RIVERSIDE, catalina@ucr.edu

\author{
Juan José Cota Nieto \\ CENTRO PARA LA BIODIVERSIDAD MARINA Y LA CONSERVACIÓN AC, \\ juan.jose@gocmarineprogram.org
}

\section{Ismael Mascareñas Osorio \\ CENTRO PARA LA BIODIVERSIDAD MARINA Y LA CONSERVACIÓN AC, ismael.mascarenas@gocmarineprogram.org}

En México la actividad pesquera más significativa es la ribereña o artesanal. La situación actual de la pesca ribereña en México muestra una urgencia por medidas de manejo pesquero participativas. El Programa Marino del Golfo de California (PMGC) creó el Programa de Ciencia Colaborativa (PCC), como mecanismo que integra el conocimiento y experiencia de pescadores y científicos para entender el estado de los recursos pesqueros comercialmente importantes, implementando técnicas innovadoras que permiten integrar la investigación participativa donde la tecnología y la confianza son componentes clave del proceso. Desde el 2009, las comunidades pesqueras de San Felipe en Baja California, El Golfo de Santa Clara en Sonora, Punta Abreojos, Puerto Adolfo López Mateos, Puerto San Carlos y Puerto Chale en Baja California Sur se han integrado al PCC para comprender el vínculo entre sus pesquerías y los recursos naturales incluyendo el componente espaciotemporal. Hasta ahora contamos con una extensa base de datos para analizar la dinámica pesquera desde una escala regional y por comunidad. El PCC tiene un impacto positivo en el cumplimiento de las metas de conservación, esta metodología tiene un valor incalculable para la investigación y el crecimiento sostenible de las comunidades. La información generada es objetiva y ha sido incorporada en procesos de toma de decisiones, en los cuales las comunidades y administradores de recursos han expuesto su interés en implementar alternativas de manejo que se adecúen a las necesidades de los usuarios.

Palabras Clave: ciencia colaborativa, comunidades costeras, Golfo de California, pesquerías artesanales, trackers.

The most significant fishing activity in Mexico is small-scale or artisanal, but the current situation of those fisheries reveals an urgent need to implement participatory fishing management approaches. In this vein, the Gulf of California Marine Program (GCMP) created the Citizen Science Program (CSP), a mechanism designed to integrate the knowledge and 
experience of fishermen with that of scientists to better understand the status of the main commercial fisheries. It incorporates tools that bring together a multidisciplinary group to conduct participatory research as a key part of a process that uses technology and seeks to build trust within the team. This program can enhance our ability to understand the interaction between people and marine resources. Since 2009, the fishing communities of San Felipe in Baja California, El Golfo de Santa Clara in Sonora, and Punta Abreojos, Puerto Adolfo López Mateos, Puerto San Carlos and Puerto Chale in Baja California Sur have been integrated into the CSP and examined the spatial and temporal interactions between artisanal fisheries and natural resources. We now have an extensive fishing database and the capacity to analyze fishing dynamics on a regional scale and by community. The CSP has a positive impact on conservation goals, and this methodology is proving to be invaluable for research and sustainable community growth. The information generated is objective and has been incorporated into decision-making processes in communities. Finally, authorities have expressed interest in implementing alternative management options that fit users' needs.

KEYwORDs: citizen science, Gulf of California, coastal fishing communities, smallscale fisheries, trackers.

Fecha de recepción: 4 de diciembre de 2016 / Fecha de aprobación: 9 de junio de 2017 / Fecha de recepción de la versión final: 4 de julio de 2017

\section{INTRODUCCIÓN}

a pesca es una de las actividades más complejas del sector primario y está influenciada por factores ambientales, económicos, culturales, sociales y políticos. México cuenta con una extensión litoral de 12,000 km y cerca de 3 millones de $\mathrm{km}^{2}$ de Zona Económica Exclusiva (ZEE), de los cuales $360,000 \mathrm{~km}^{2}$ son de plataforma continental ( 0 a 200 metros de profundidad), y es justo en esta zona donde se desarrolla la mayoría de la actividad pesquera del país (figura 1).

En las costas mexicanas existe una gran diversidad de especies comerciales, principalmente en el Golfo de California, donde la pesca se ha convertido en una importante fuente de empleo y sustento para las comunidades costeras (INE 2004, 94-117). Los registros oficiales de INEGI indican que hay en el país alrededor de 300,000 pescadores, pero si se consideran empleos indirectos y las familias de estos empleados, se estima que alrededor de 12 millones de mexicanos están directa o indirectamente ligados a las actividades del sector pesquero (Arreguín Sánchez 2006, 384). 


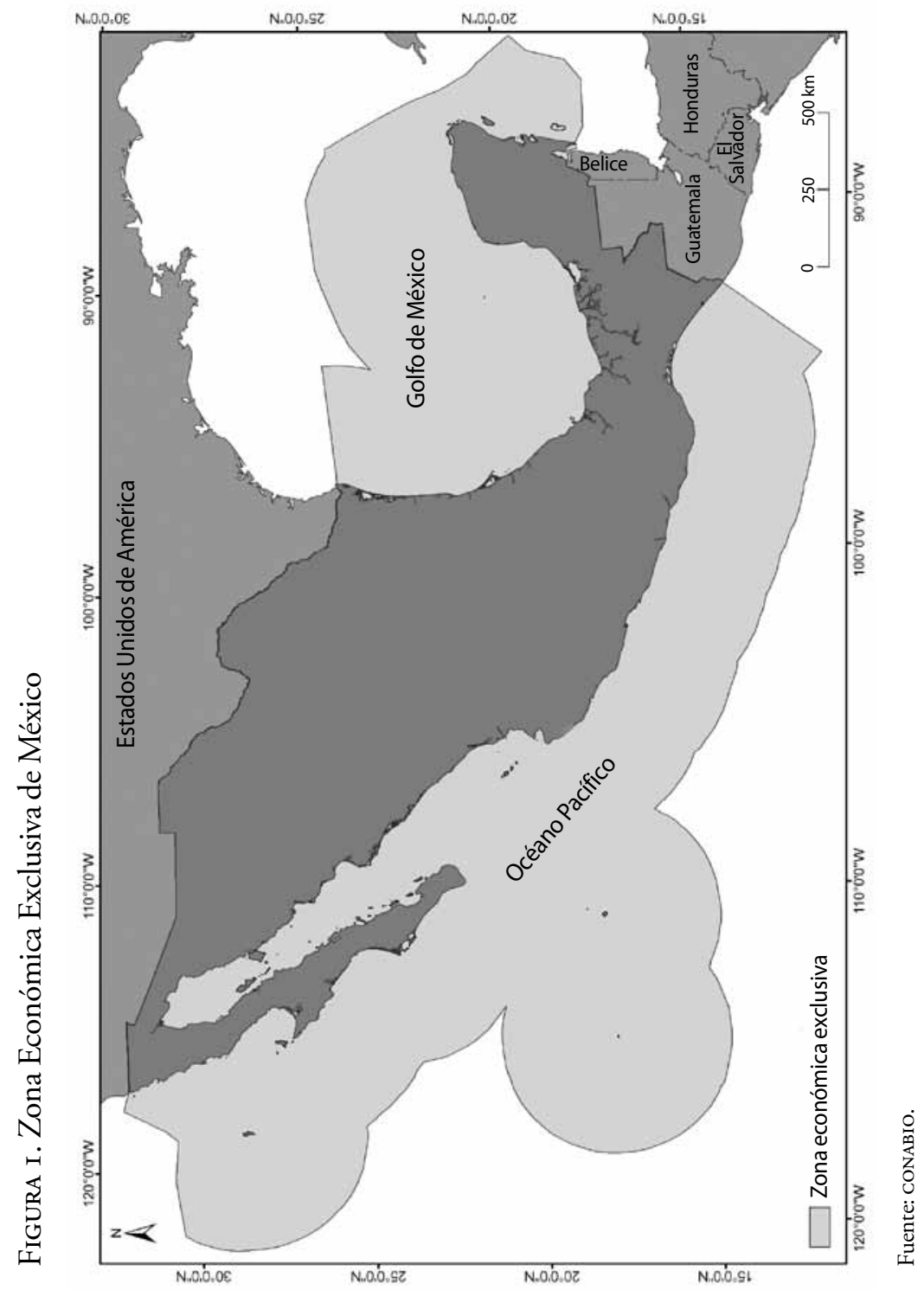


Figura 2. Pirámide de intermediación en el proceso de comercialización del producto pesquero

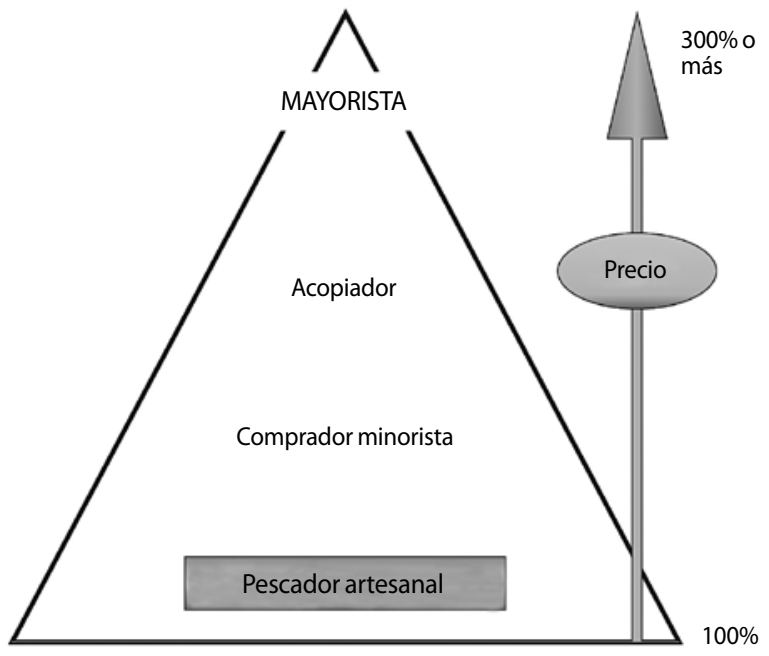

Fuente: Villegas Calzada 2012.

En México se desembarcan en promedio 1.1 millones de toneladas anuales de productos pesqueros, de los cuales, por lo menos, $70 \%$ se obtiene en la región noroeste del país. La actividad pesquera más significativa desde la perspectiva social, económica y ecológica es la ribereńa, artesanal o de pequeña escala. A nivel nacional, la pesca ribereńa emplea a $85 \%$ de los pescadores y arriba de $90 \%$ de las más de 102,000 embarcaciones registradas (Díaz-Uribe et al., 2013, 41-45). La pesca ribereña basa su producción en escama: huachinangos y pargos, curvinas, cabrillas, robalos, mojarras; además de la captura de tiburones. En cuanto a crustáceos, la producción está compuesta por camarón, jaibas y langosta. El producto se vende de manera local y son los intermediarios los encargados de la distribución y comercialización del producto. En la figura 2 se observa al pescador artesanal ocupar el nivel más bajo en la comercialización del producto y, en ocasiones, el precio puede llegar a incrementarse hasta en $300 \%$ debido a los intermediarios. 
Los principales problemas del sector ribereńo son los altos costos de combustible, disminución de las capturas, el alto esfuerzo pesquero, la pesca ilegal, ${ }^{1}$ captura de organismos juveniles o especies no objetivo, falta de políticas públicas enfocadas a una pesca sostenible que genere bienestar para los trabajadores y las comunidades (Bravo-Olivas et al., 2014, 110-142). Los pescadores ribereńos se encuentran en desventaja para operar eficientemente en los mercados, en parte por la mínima atención recibida de las autoridades. Al mismo tiempo, el sector ribereño se enfrenta al reto de generar más empleos, convertirse en una actividad sustentable ${ }^{2}$ (Díaz-Uribe $e t$ al., 2013, 41-45). Las pesquerías ribereñas hacen uso exhaustivo de los ecosistemas costeros, lo que genera algunos conflictos con otros usuarios, ya sea por interferencia con otras actividades (por ejemplo, el turismo) o debido a la percepción pública con respecto a la conservación de la biodiversidad.

El manejo de las pesquerías ribereñas es difícil, ya que no siempre se cuenta con suficiente información que ayude a analizar la salud de las poblaciones aprovechadas y entender los procesos ambientales que regulan las especies (Salas et al., 2007, 5-16). Idealmente, el manejo pesquero debe ser un proceso dinámico basado en el conocimiento científico, pero el manejo pesquero tradicional se ha basado en estimar las capturas pesqueras para poder calcular la intensidad de la pesca. Si bien, la información de capturas pesqueras es útil, ésta no resuelve una de las interrogantes fundamentales: la relación entre los recursos marinos y el uso humano desde las dimensiones espacial y temporal (López-Sagástegui et al., 2014, 1-6). Un atributo importante de las pesquerías ribereñas es su estrecha relación con la identidad personal y cultural de los pescadores. Ellos perciben la pesca no sólo como un medio de sustento, sino como un

${ }^{1}$ La pesca que se realiza en contravención de las disposiciones legales mexicanas: Ley General de Pesca y Acuacultura Sustentables, Ley de Pesca, 39 Normas Oficiales Mexicanas Pesqueras y Acuícolas (NOM). Aquella que se realiza sin permiso expedido por CONAPESCA; pesca en zonas prohibidas (bahías, esteros, ANP, refugios pesqueros, etcétera); no respetar vedas, utiliza artes de pesca no permitidos, etcétera.

${ }^{2}$ El desarrollo sustentable es un modelo que permite el equilibrio entre el crecimiento y el desarrollo económico con el desarrollo social, mientras protege al ambiente, que logra así la conciliación entre hombre, naturaleza y economía (Salcedo et al., 2010). 
modo de vida fortalecido por valores que fundamentan aspectos decisivos de su identidad cultural. De acuerdo con la FAO, ${ }^{3}$ se deben considerar las características socioculturales que viven los pescadores ribereños; reconocer su derecho a espacios de pesca; y promover la participación activa de los actores en la gobernanza del recurso para alcanzar un manejo pesquero que genere beneficios económicos, sociales y culturales.

La situación actual de la pesca ribereña en México muestra una urgencia por medidas de manejo pesquero participativas. Las comunidades costeras deben participar en actividades de investigación (ciencia colaborativa) y en el diseńo de estrategias de ordenamiento pesquero (comanejo) para recuperar recursos sobreexplotados y proteger aquellos que se aprovechan de manera sustentable (FAO 2010,30). Es necesario integrar la información sobre el recurso, el medio ambiente, la distribución espacial y temporal del recurso y del esfuerzo pesquero, la producción pesquera, los artes de pesca utilizados son claves para diseńar un manejo pesquero adecuado (INE 2000, 77-101). Un factor fundamental para la ordenación efectiva de las pesquerías es contar con una caracterización socioeconómica de las comunidades costeras, conocer la percepción de los pescadores respecto a los problemas y retos que enfrentan como sector. Adquirir esta información requiere de la participación de diversos sectores sociales y nos obliga a la búsqueda de enfoques de manejo comunitario y a valorar el uso del conocimiento empírico de los pescadores (Amezcua 2011).

\section{Pesca en el Golfo de California}

El Golfo de California es uno de los sitios con mayor biodiversidad marina a nivel mundial, incluyendo lagunas de crianza de ballenas, hábitats esenciales para la tortuga marina y zonas de anidación para cientos de especies de aves. Esta región incluye áreas marinas prioritarias de conservación (APC): Corredor Los Cabos/Loreto; Alto Golfo

${ }^{3}$ Organización de las Naciones Unidad para la Alimentación y la Agricultura (por sus siglas en inglés: Food and Agriculture Organization). 
Figura 3. Mapa del Golfo de California compuesto por los estados de Baja California, Sonora, Sinaloa, Baja California Sur y Nayarit

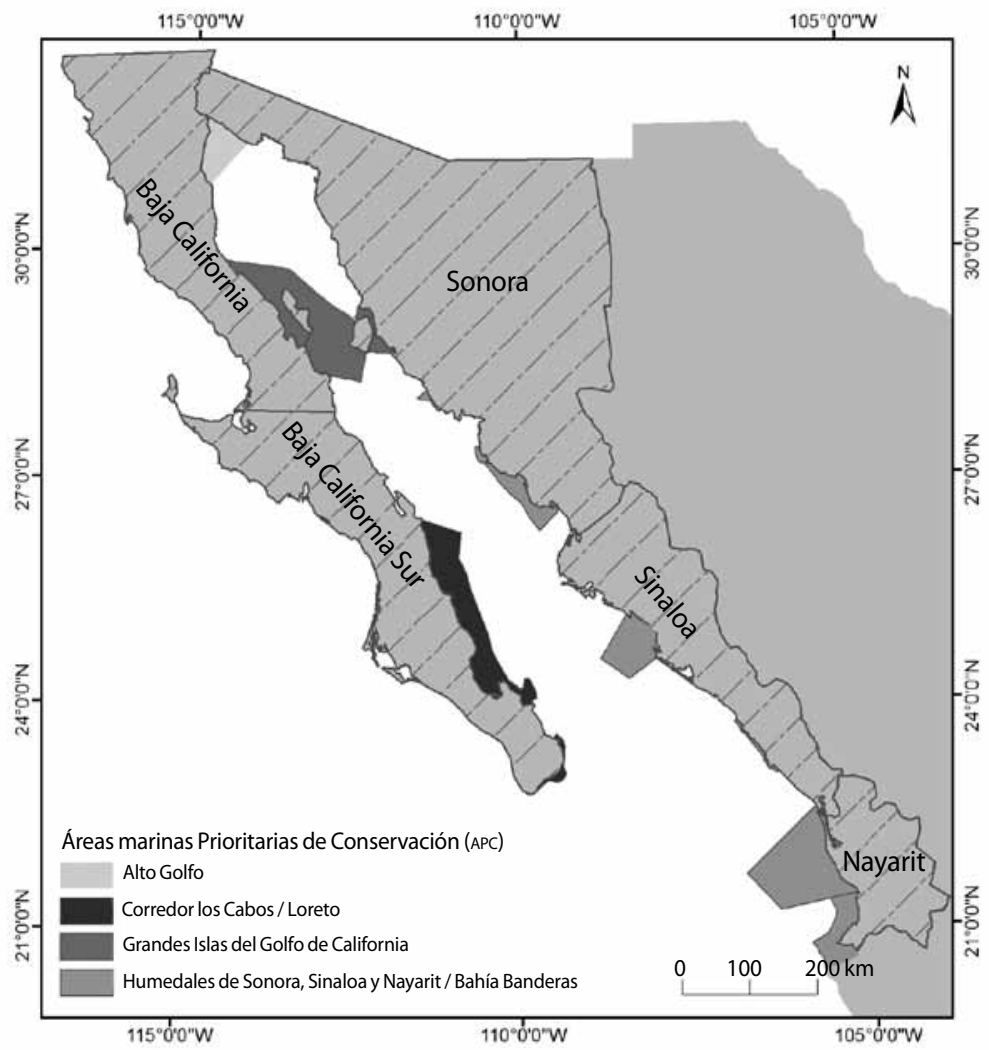

Fuente: Morgan et al., 2005.

de California; Grandes Islas del Golfo de California/Bahía de Los Ángeles y Humedales de Sonora, Sinaloa y Nayarit/Bahía de Banderas (figura 3) (Wilkinson et al., 2009, 200).

Es una de las zonas de pesca más productivas de México, resultado de la topografía, latitud y las surgencias, que contribuyen a mantener una productividad primaria alta durante casi todo el año. La región está sometida a una variabilidad interanual de episodios 
oceanográficos-atmosféricos, que influyen en la distribución, abundancia y disponibilidad de los recursos marinos y pesqueros (Cortés et al., 2006, 23). En el litoral peninsular predominan fondos rocosos por lo que prevalecen los recursos como huachinango, pargo, cabrillas, jurel y el tiburón; en el litoral continental la descarga de ríos favorece la presencia de estuarios y se observa mayor cobertura de costas con fondos arenosos, lo que se relaciona con la predominancia de especies como camarón, lisa, la mojarra y curvina (DíazUribe et al., 2013, 41-45).

La intensidad de la pesca rebasa los niveles sustentables para la mayoría de las pesquerías de interés comercial (camarón, jaiba, varias especies de almejas, callo de hacha, curvina, chano), diversas especies de tiburones, rayas y mantas, además de los preocupantes declives en la abundancia de especies endémicas como la totoaba o la vaquita marina (en peligro crítico) (Wilkinson et al., 2009, 200). Durante muchos ańos, la pesca artesanal pudo sostenerse, pero a medida que las especies objetivo tradicionales comenzaron a disminuir, los pescadores adoptaron otros tipos de artes de pesca y reorientaron sus esfuerzos hacia otras especies que en décadas anteriores no solían estar en los avisos de arribo como el perico, pierna o huachinango (Aburto-Oropeza et al., 2016, 8). Sin embargo, la pesca no es la única razón de la disminución de recursos pesqueros, la desviación de aguas fluviales, la sedimentación, la contaminación y el establecimiento de granjas acuícolas han alterado los ecosistemas de la región, lo que ha tenido como consecuencia un decremento en la biodiversidad de la región. El ejemplo más claro está en el Alto Golfo de California, donde son innegables los cambios de las condiciones originales del ecosistema debido al descenso en el aporte de agua dulce proveniente del río Colorado, que ha modificado drásticamente las condiciones ecológicas de lo que solía ser un importante sistema estuarino y una zona de gran importancia para la reproducción, desove y crianza de gran variedad de organismos marinos como el camarón, la totoaba y la curvina golfina (Brusca et al., 2017). En 1935, el flujo anual del río Colorado era de casi $500 \mathrm{~m}^{3}$ y contribuía con $59 \%$ del total de agua dulce que ingresaba al Golfo de California (Orozco 1998, 1002-1011). Debi- 
do a las presas en el río Colorado, éste ya no fluye libremente, lo que ha generado importantes daños ecológicos y pérdida de calidad de hábitat en la cuenca (Hinojosa y Carrillo 2010, 180-187). Desde la perspectiva de los pescadores, la reducción del aporte de agua del río Colorado ha reducido también el volumen de producción pesquera.

El Golfo de California ha atraído la atención de Organizaciones de la Sociedad Civil (osc) e investigadores dedicados a la conservación y el manejo de los recursos naturales. En toda la región, la lucha entre el sector conservación y los pescadores no permitía llegar a esquemas de manejo pesquero exitosos, la historia de tensión entre científicos y pescadores surge en los ochenta, cuando se descubrió que la población de vaquita estaba siendo capturada de manera incidental en las redes agalleras utilizadas para la captura de la totoaba (López-Sagástegui et al., 2010, 26). La falta de colaboración entre el sector de conservación y pesquero ha resultado en una reducción dramática de las opciones de manejo en la región (Aburto-Oropeza et al., 2016, 8).

El Programa Marino del Golfo de California (PMGC), un grupo multidisciplinario de investigadores, estudiantes y profesionales pertenecientes a distintas instituciones, entre ellas, el Centro para la Biodiversidad Marina y la Conservación A.C. (свмс) en La Paz; el Instituto de Oceanografía Scripps (sio) de la Universidad de California en San Diego; y el Instituto para México y Estados Unidos (uCMEXus) de la Universidad de California en Riverside, comenzó en el 2009 uno de sus programas de investigación, en el cual la participación ciudadana es elemental. Uno de los objetivos del PMGC es entender la relación entre la pesca, la biodiversidad de los ecosistemas marinos y costeros y la dinámica socioeconómica.

\section{Programa de Ciencia Colaborativa}

El manejo sustentable de los ecosistemas asegura la continuidad de cualquier actividad que dependa de los recursos naturales (pesca, turismo). El reto es conocer dónde se desarrollan estas actividades; qué especies pescan; cuánto esfuerzo pesquero realizan; cuánto tiempo invierten; y qué efecto tienen sobre sus actividades pesque- 
ras las políticas de manejo. Incorporar este conocimiento a los esquemas de manejo pesquero es crucial para proteger los ecosistemas marinos y los servicios que proveen.

El PMGC busca implementar una nueva manera de hacer ciencia para entender las conexiones entre los ecosistemas marinos y la actividad humana. De acuerdo con Santos (2000, 38-39) el espacio adquiere contenido a partir del reconocimiento de los vínculos entre los individuos y la sociedad; pensar una metodología para responder interrogantes de análisis del espacio que permitan tener en cuenta los integrantes sociales y naturales que componen el espacio.

El PMGC aborda los desafíos de la conservación de manera multidisciplinaria, enfocándose en la generación y difusión de información científica para incidir de manera positiva en el manejo y la conservación de los recursos. Se colectan datos sobre la ecología marina, taxonomía y biodiversidad, información espacio-temporal y socioeconómica y se analiza desde una perspectiva científica, económica, política y social. Lo que distingue al PMGC es que prioriza y pone énfasis en las comunidades locales, usuarias de los recursos naturales. Bajo esta perspectiva el PMGC creó el Programa de Ciencia Colaborativa (PCC), para integrar a las comunidades en el trabajo científico y poder entender el estado de los recursos pesqueros comercialmente importantes para ellas y la relación que tienen con el hábitat y sus recursos. Es una metodología basada en la construcción de relaciones de colaboración entre científicos y los usuarios de uno o varios recursos (por ejemplo, turistas, pescadores, estudiantes) y busca involucrarlos en procesos de investigación científica, esto permite que se formulen objetivos y metas de manera conjunta (López-Sagástegui et al., 2014, 1-6). Lograr el acceso a información detallada es sumamente difícil sin la ayuda de las comunidades, que aprovechan y conocen el medio ambiente en el que trabajan. La clave del programa es mantener una comunicación abierta y transparente, garantizar el acceso libre a la información para incentivar la participación de pescadores en la generación de datos, un proceso de ciencia transparente resulta en mayor participación en el diseño de políticas públicas.

El PCC se establece por primera vez en el Alto Golfo de California en 2009, con el objetivo de estudiar las pesquerías y la dinámica 
socioeconómica de la región; el Programa de Acción para la Conservación de la Vaquita apenas comenzaba y existía tensión entre investigadores y pescadores. Los pescadores locales inicialmente tuvieron reservas sobre unirse al PCC, pero con el paso del tiempo se demostró que el programa respondía a una de sus inquietudes: la falta de datos confiables para la toma de decisiones. El conocimiento científico multidisciplinario cobra importancia cuando resulta útil para muchos; la pesca y la conservación se deben abordar desde muchos puntos de vista, ya que son actividades que siempre están interactuando e influyen en otros sectores (López-Ságastegui y AburtoOropeza, 2016). El PMGC mantiene una fuerte colaboración con los pescadores y las comunidades locales a través del PCC, con el fin de generar datos pesqueros, biológicos, económicos y espaciales en distintas comunidades.

La herramienta principal del PCC son los trackers o GPS data Logger, ${ }^{4}$ los cuales colectan información espacial para trazar los viajes de pesca, sitios de pesca (waypoints), duración de la jornada, mapear las áreas de pesca y entender cómo se distribuye el esfuerzo pesquero en la región. La colecta, captura, transferencia y comunicación de los datos generados en las comunidades se lleva a cabo por coordinadores comunitarios y los pescadores. Los coordinadores comunitarios preparan los trackers y los entregan a cada pescador al momento de salir a pescar, el tracker está encendido durante toda la jornada de trabajo y registra las coordenadas (latitud, longitud) de un viaje de pesca de cada 5 a 30 segundos. Al regresar, el coordinador comunitario recoge el tracker y registra las especies que se pescaron, el método de pesca utilizado y el volumen de captura $(\mathrm{kg})$ (Moreno-Báez et al., 2014, 32). Además, los coordinadores y otros miembros de las comunidades se capacitan con el PMGC para generar información sobre el peso, talla, sexo, edad y madurez de los peces. Al ser una investigación que involucra diversas variables, es necesario usar una herramienta que permita trabajar con la información de manera integrada, en la cual los resultados puedan ser fácilmente interpretados, siendo aquí indispensable el uso de Siste-

${ }^{4}$ Dispositivos de posicionamiento global. 
Figura 4. Diagrama de Flujo de las actividades de colecta, captura, transferencia y comunicación de los datos e información

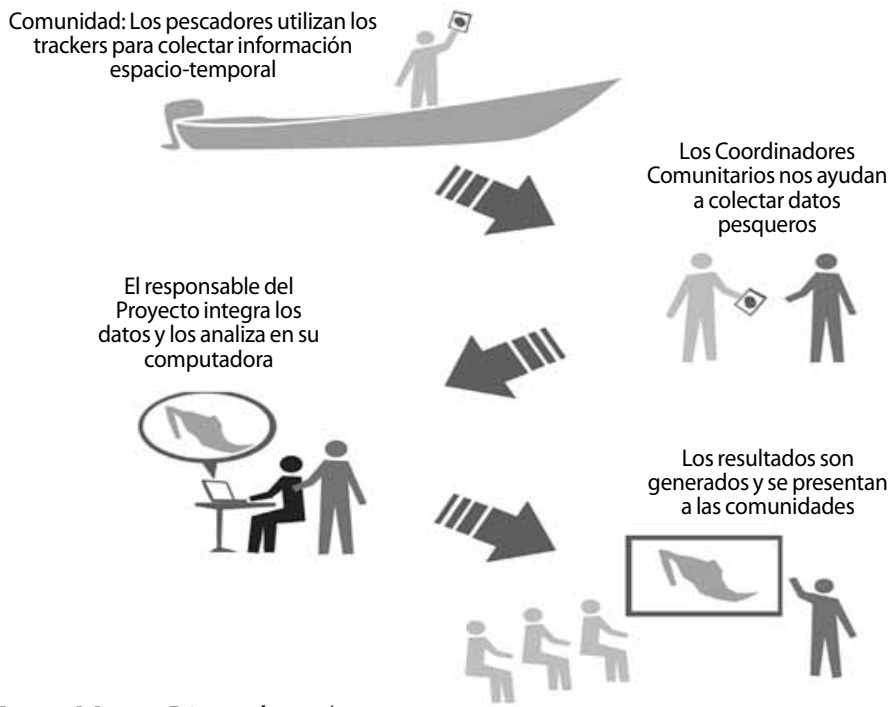

Fuente: Moreno-Báez et al., 2014.

mas de Información Geográfica (sIG) (figura 4). Los resultados se presentan a las comunidades, ya sea como gráficos, mapas u otro material de comunicación que ayude a entablar diálogos sobre temas técnicos en un lenguaje coloquial. Este paso es clave, ya que los pescadores juegan un papel importante en el análisis de información e interpretación de resultados, y es durante este paso que integramos su conocimiento y experiencia.

A través de estas colaboraciones se han identificado lugares de desove de especies de importancia comercial, cambios en el esfuerzo pesquero durante el periodo de desove, estructuras de tallas y edades de las capturas pesqueras. Las relaciones de colaboración entre la comunidad y el PMGC demuestran el gran potencial que tiene la participación ciudadana en la ciencia (López-Ságastegui 2014). Estamos dispuestos a aprender de los pescadores, ya que aportan una perspectiva única: cuando nosotros vemos un patrón de variancia, ellos ven el efecto de eventos naturales como huracanes, eventos 
políticos como restricciones espaciales en la pesca o el incremento en el número de permisos, o el efecto de eventos económicos como la variación del precio del producto (López-Sagástegui et al., 2014, 1-6). La contribución del PCC a la investigación y al crecimiento sostenible de la región es invaluable.

\section{Cada COMUnidad es Distinta}

Hemos aprendido que cada comunidad es distinta, cada una de ellas con necesidades e interrogantes particulares que resolver, por esto, debe conocerse la dinámica social, política y económica que vive cada comunidad donde se pretende implementar un programa de investigación colaborativo como el PCC.

En el 2009, empezamos a trabajar en el Golfo de Santa Clara, Sonora, una comunidad localizada dentro de la Reserva de la Biosfera del Alto Golfo de California y Delta del Río Colorado para estudiar a la curvina golfina, y el efecto que la pesca tiene sobre su población. La información que generamos es utilizada para alimentar el proceso de manejo de esta pesquería y, más importante aún, es información en la que la comunidad confía. A petición de la comunidad, integramos más pesquerías a la metodología, e incluso fuimos invitados por pescadores de San Felipe, Baja California, otra comunidad que utiliza la zona de amortiguamiento de la reserva para pescar, a utilizar este método de investigación en sus pesquerías. También en el 2009 comenzamos nuestra colaboración en Punta Abreojos, Baja California Sur, para estudiar la dinámica pesquera en esa región enfocando el esfuerzo en las pesquerías más importantes: verdillo, curvina y lenguado. En 2012 iniciamos en Bahía Magdalena-Almejas y en Bahía de La Paz para estudiar las pesquerías de huachinango, jurel, verdillo, vieja, camarón, entre otras (figura 5).

Actualmente contamos con un banco de datos de más de 15 mil viajes de pesca, 67 especies registradas de 6 distintas comunidades pesqueras en el Golfo de California y costa occidental de la península en вCs, lo que nos permite analizar la dinámica pesquera desde un punto de vista regional o por comunidad. Esta base de datos incluye información espacial, temporal, biológica, económica y capturas 
Figura 5. Mapa de comunidades que integran el Programa de Ciencia Ciudadana

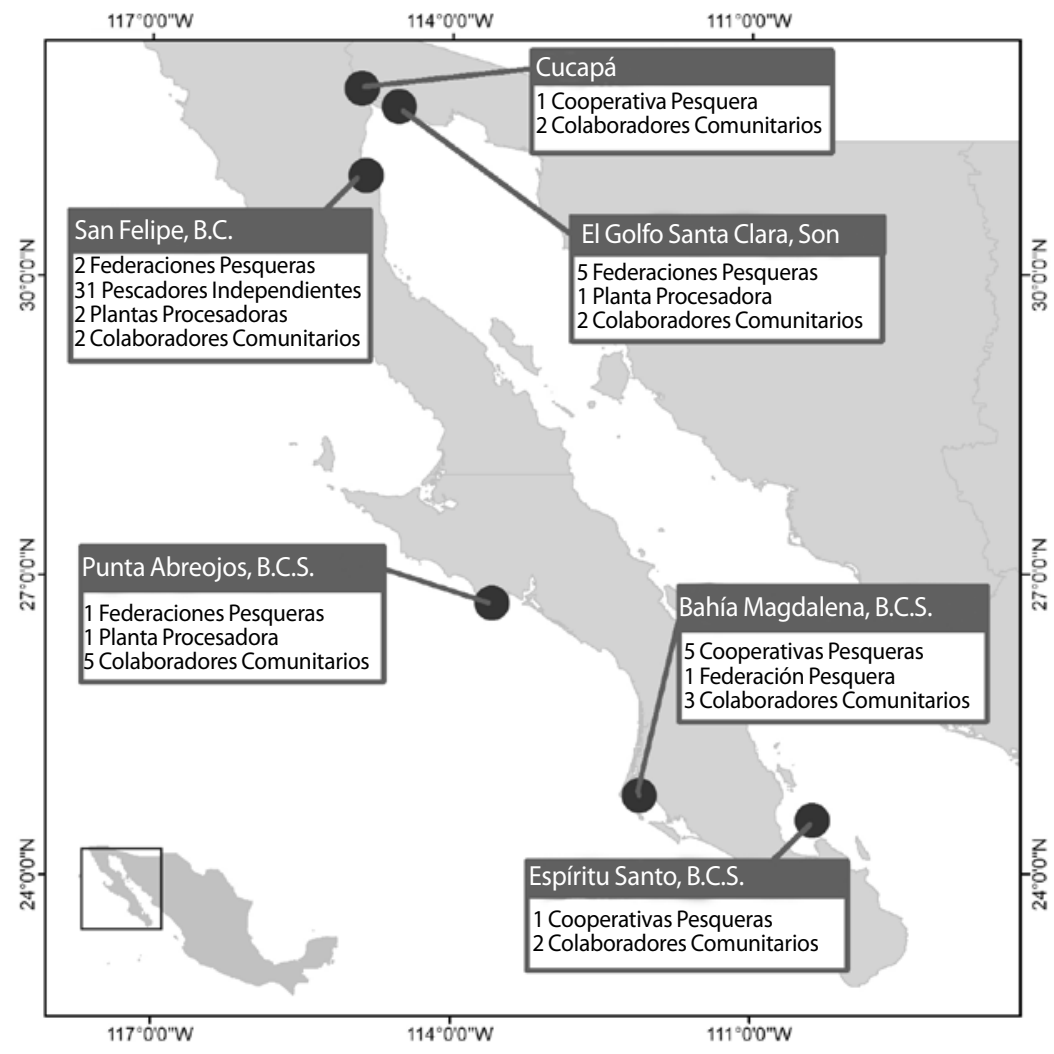

Fuente: Gulf of California Marine Program 2014.

pesqueras, relacionada con las especies objetivo. Para algunas pesquerías hemos podido delimitar los sitios pesqueros más importantes, además de describir físicamente que áreas son las más productivas y visitadas por los pescadores, y con la información biológica estamos contribuyendo al conocimiento de la ecología y biología de las especies objetivo (figura 6).

El manejo pesquero está enfocado en aspectos biológicos de las especies, dejando a un lado aspectos como bienestar social, econó- 


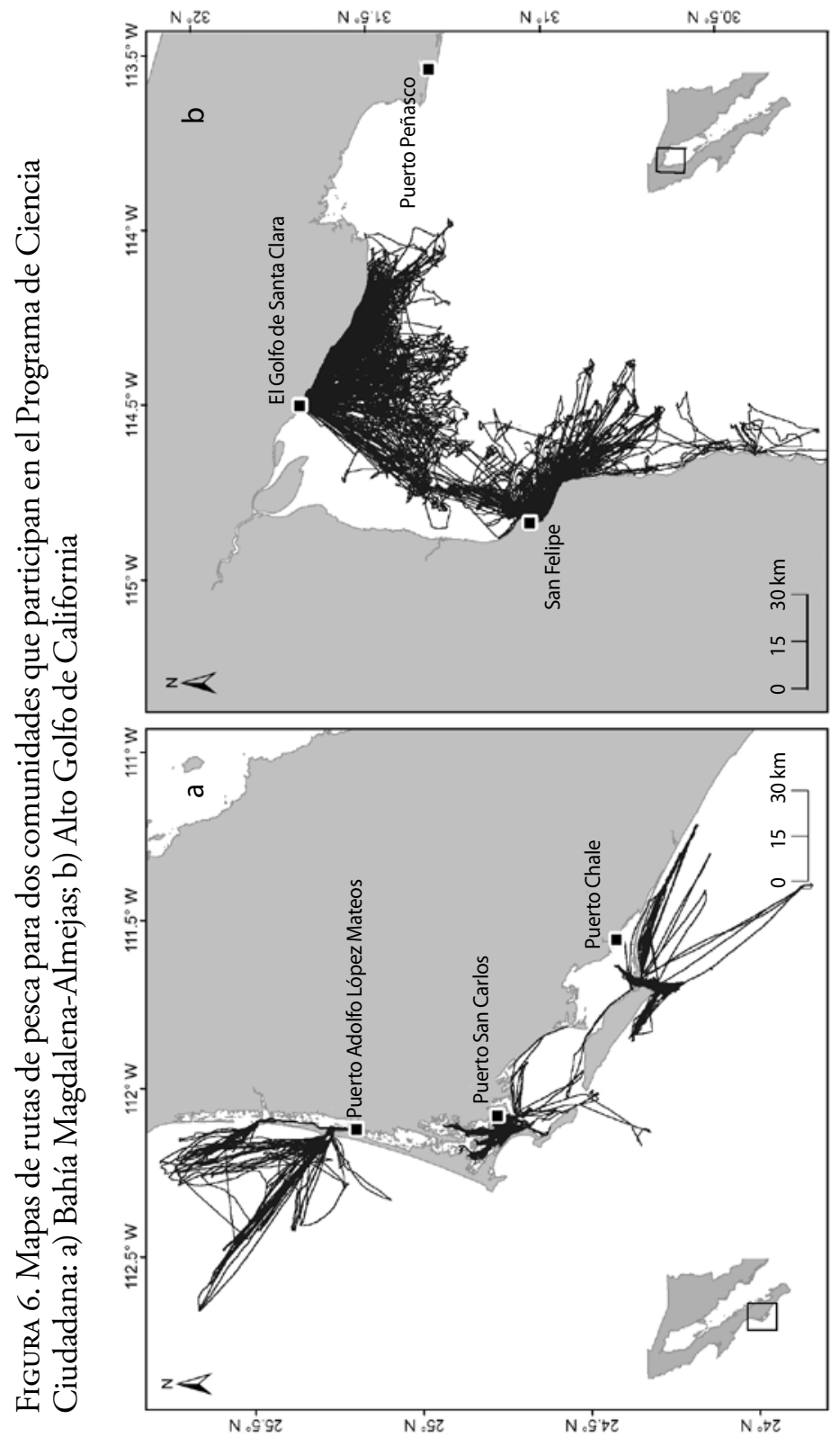


mico y cultural. Las pesquerías son más que zonas geográficas o artes de pesca o especies comerciales importantes, son un fenómeno humano. Para que las comunidades pesqueras acepten y se apropien de los esquemas de manejo es necesario atender sus preocupaciones y considerar sus necesidades sociales, culturales y económicas. La metodología que implementamos busca garantizar la participación activa de las comunidades que aprovechan y dependen de los recursos marinos.

\section{Alto Golfo de California}

La historia del Alto Golfo es de tradición pesquera, trae consigo un fuerte legado, la herencia de padres y abuelos que los impulsa a dedicarse a la pesquería artesanal. Las tres principales comunidades de la región son San Felipe, en Baja California; El Golfo de Santa Clara; y Puerto Peńasco, en Sonora. Las tres comunidades fueron fundadas a principios del siglo xx como campos pesqueros; no obstante, en la actualidad, cada una posee una estructura económica diferente. En San Felipe y Puerto Peńasco, el turismo y la pesca son actividades productivas igualmente importantes; mientras en El Golfo de Santa Clara, 80 \% del sustento económico proviene de la pesca artesanal (López-Sagástegui et al., 2010, 26).

El Alto Golfo de California es una de las zonas pesqueras más importantes de México, actualmente en el Golfo de Santa Clara hay 457 pangas registradas que en conjunto cuentan con 925 permisos de pesca para 20 pesquerías; mientras que en San Felipe hay 204 pangas, con 547 permisos de pesca para 27 pesquerías (Pérez-Valencia et al., 2015, 234). La flota pesquera ribereña de ambas comunidades se distingue por su interacción con dos especies marinas endémicas y en peligro de extinción: la vaquita marina y la totoaba.

Durante la primera mitad del siglo xx, las pesquerías de totoaba y tiburón atrajeron a pescadores de Sonora y Sinaloa, pero en los setenta la actividad pesquera se enfocó en la captura de camarón, que es hasta ahora la especie más importante del Alto Golfo de California en términos económicos (Johnson et al., 2015). A finales de los setenta la captura de totoaba había caído drásticamente y el go- 
bierno decidió declarar una veda total de la especie, más tarde se descubrió que existía el riesgo de que la vaquita marina fuera capturada incidentalmente en las redes de enmalle utilizadas en la pesquería de camarón ${ }^{5}$ (Rodríguez-Valencia y Cisneros-Mara 2006, 127). En los noventa se realizaron diversos estudios para estimar el tamaño de la población de vaquita marina y se concluyó que también se encontraba en peligro de extinción (Vidal 1995, 247-272). Estos registros de muerte incidental llamaron la atención de científicos y grupos de conservación, y a partir de este momento los esfuerzos de conservación se comenzaron a enfocar en la protección de la vaquita (Cudney-Bueno y Turk-Boyer 1998, 175).

En 1997, el gobierno mexicano establece distintos comités científicos en un esfuerzo por evitar la extinción de la vaquita marina, sin embargo, estos comités no brindaban medidas de manejo que cumplieran con la filosofía de la sustentabilidad, ${ }^{6}$ y como resultado los pescadores comenzaron a sentirse afectados. Esto, junto con la creciente presión internacional, incrementó las tensiones entre el sector conservación y el pesquero. Con los años, los conflictos se han vuelto recurrentes, el sector pesquero presiona a las autoridades para frenar las políticas restrictivas sobre la pesca y el sector conservación busca adoptar políticas más restrictivas que parecen ignorar el impacto económico que tendrían sobre las comunidades (LópezSagástegui et al., 2010, 26). Mientras que a los esfuerzos de conservación de especies en peligro les falte visión de largo plazo y descuiden el lado humano, el éxito de la conservación será cuestionable. La exclusión de actores clave en el proceso de toma de decisiones puede resultar en una falta de confianza y la polarización de grupos (Aburto-Oropeza et al., 2016, 8).

Romper con una larga historia de tensiones y promover la participación de los pescadores en la investigación no es tarea fácil; mantener

${ }^{5}$ NOM-002. Véase Modificación a la Norma Oficial Mexicana NOM-002PESC-1993. 2006. Para ordenar el aprovechamiento de las especies de camarón en aguas de jurisdicción federal de los Estados Unidos Mexicanos.

${ }^{6}$ Cualidad de los sistemas humanos en interacción con la naturaleza para asegurar el uso de los recursos y que los ciclos naturales no afecten la calidad de vida, ni la pérdida de oportunidades futuras para el desarrollo económico, social, de salud y del medio ambiente (Mihelcic 2003 en González-Rosales y López-Torres 2015). 
un intercambio de conocimientos entre científicos, pescadores, OsC y gobierno se ha vuelto una prioridad. En una muestra de interés por parte del entonces Comisionado de Pesca, ingeniero Ramón Corral, para comenzar a ordenar y mejorar la administración de los recursos pesqueros en esta región, invitó al PMGC a trabajar con los pescadores y otros investigadores para llenar los huecos de información que existían sobre una de las pesquerías más importantes de la región: la curvina golfina. El trabajo colaborativo nos permitió mostrar cómo se forma una agregación reproductiva (Erisman et al., 2012, 1-11), entendimos la relación del desove con las mareas y la luna (Jiménez-Esquivel y Mascareńas-Osorio 2015), y obtuvimos a detalle las tendencias de captura (Erisman et al., 2015, 254-265). La información ha sido utilizada por pescadores, gobierno y osc en el manejo de esta pesquería (Ortiz et al., 2016); ha ayudado a entender la dinámica del mercado de esta especie (EDF 2015, 1-10), así como complementado los análisis utilizados para definir las cuotas de captura. En 2010, al quedar claros los beneficios de nuestro programa y su metodología, integramos las pesquerías de sierra, chano y camarón, y ampliamos nuestro programa para incluir a San Felipe y el Indiviso en Baja California.

A finales del 2014, comprobamos cómo nuestra metodología contribuía a mantener un diálogo entre autoridades, pescadores y osc, cuando el presidente Enrique Peńa Nieto anunció la suspensión del uso de redes de enmalle durante dos años, como parte de un histórico esfuerzo por salvar a la vaquita marina, la cual comenzó en mayo de 2015 (Dof 2015). Esta suspensión incluye un programa de compensación económica para los pescadores de San Felipe y el Golfo de Santa Clara. Los líderes de pesca del Golfo de Santa Clara y San Felipe solicitaron un ejercicio de valuación de sus pesquerías, utilizando los datos que los pescadores han ayudado a generar. Estimamos las ganancias totales para las pesquerías más importantes de la región que utilizan chinchorro de línea: chano, curvina golfina, camarón y sierra. Después de 6 años en la región, generamos información de 5,150 viajes de pesca de 649 pangas: 58 \% de camarón, $24 \%$ de chano, $9 \%$ de curvina golfina y $9 \%$ de sierra. Utilizamos el número de permisos de pesca como indicador de número de pan- 
Figura 7. Ganancias económicas de la pesquería de curvina del Alto Golfo de California

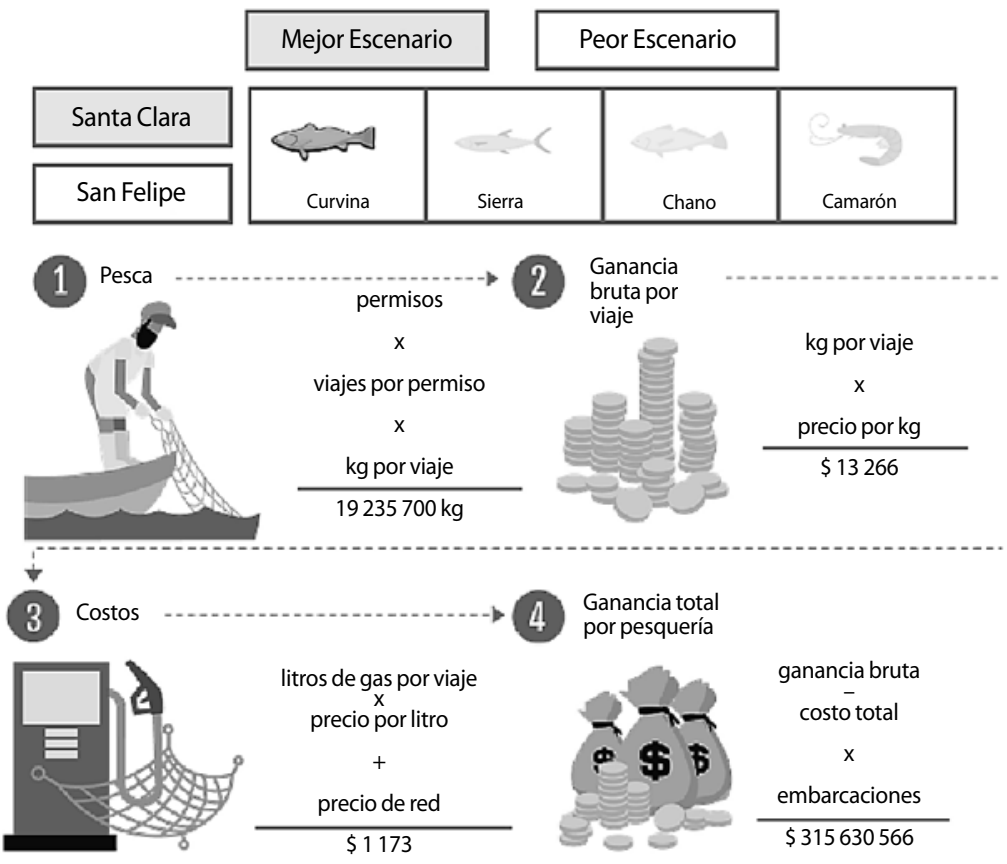

Para ver los resultados obtenidos del análisis de ganancias económicas para las pesquerías de chano, sierra y camarón visitar http://datamares.ucsd.edu/esp/valor-de-la-actividad-pesquera-en-elalto-golfo-de-california/

Fuente: Programa Ciencia Ciudadana del Programa Marino del Golfo de California.

gas. El costo de gasolina se basó en el gasto promedio por viaje y el promedio de los precios de mercado registrados durante octubre 2014. Para calcular el costo de la red dividimos el precio total de la red entre el promedio de viajes en cada pesquería. Además, obtuvimos un promedio de los precios de mercado provenientes de compradores locales del 2011 al 2013 para pescados y camarón para obtener el mejor y el peor escenario (figura 7). Estimamos que dejar de pescar durante un año representa una pérdida total aproximada 
de 972 millones de pesos para ambas comunidades. Las ganancias perdidas por panga en cada comunidad alcanzarían 1.71 millones de pesos para el Golfo de Santa Clara y 1.18 millones de pesos para San Felipe (López-Ságastegui et al., 2016). Nuestras estimaciones fueron casi el doble de las presentadas por el gobierno, pero es importante notar que no incluimos todos los costos asociados a la actividad. Por primera vez, los pescadores contaban con un respaldo científico que les permitía negociar con el gobierno; esto ha reafirmado el compromiso que los pescadores tienen con el PCC. Los pescadores deben ser incluidos en el diseño de iniciativas de conservación, si se integra el bienestar social a las estrategias de conservación y manejo pesquero es más probable que las medidas implementadas sean exitosas.

\section{Punta Abreojos}

El PCC no sólo se utiliza en zonas donde el conflicto entre sectores impide avanzar en objetivos de conservación y manejo de recursos. Desde el 2009, trabajamos con la Sociedad Cooperativa de Producción Pesquera Punta Abreojos S.C. de R.L., analizando sus patrones de aprovechamiento para ayudar a diseñar estrategias de manejo que beneficien a la cooperativa sin arriesgar la salud de la población de los recursos. La cooperativa es conocida internacionalmente como un caso exitoso en manejo pesquero y desarrollo sostenible en el noroeste del Pacífico mexicano (Cota-Nieto 2012). Las primeras familias que se instalaron en Punta Abreojos eran de pescadores provenientes de Ensenada, Baja California y San Ignacio, Baja California Sur. Las pesquerías de abulón y langosta han representado una de las actividades pesqueras más importantes para el país y para la región. Estos productos se exportan a Singapur, China, Japón, Estados Unidos y Francia.

En 1948 se consolidó la Sociedad Cooperativa de Producción Pesquera Punta Abreojos; la langosta roja y el abulón fueron los recursos más importantes para Punta Abreojos, pero a partir de los ochenta la Cooperativa empezó a diversificar sus pesquerías como estrategia para subsanar la notable caída en las capturas de abulón y proteger la pesquería de la langosta (Cota-Nieto et al., 2015). La coo- 
perativa reconoce la importancia de usar herramientas que faciliten la visualización, análisis e interpretación de sus registros pesqueros para así mejorar la administración y comercialización de sus productos pesqueros. En el 2004, la pesquería de langosta en la región fue certificada por el Consejo de Administración Marina (MSC, por sus siglas en inglés) acreditándola como sostenible, basándose en una evaluación que se realizó durante tres ańos (Vega-Velázquez 2004, 52). Actualmente se capturan más de 25 especies y las artes de pesca que se emplean incluyen chinchorros, trampas y buceo tipo hoocka.

Para la Cooperativa, nuestro PCC resultó atractivo, ya que buscaban tomar el liderazgo en el estudio y monitoreo de sus recursos pesqueros. En colaboración con la cooperativa hemos documentado la dinámica pesquera y esto nos ha permitido identificar las tendencias de capturas y el beneficio económico que se genera para la comunidad. La base de datos incluye la información espacial, temporal, de capturas pesqueras y económica relacionada con las especies objetivo y la actividad pesquera desde el verano de 2009 hasta marzo de 2013.

Además de realizar el monitoreo pesquero tradicional, hemos integrado características sugeridas por los pescadores. De acuerdo con entrevistas a miembros de la cooperativa, se clasificaron los recursos en tres grupos: culturales (langosta y abulón), pesquerías pioneras que impulsaron el desarrollo socioeconómico de la comunidad; recursos objetivo (verdillo, jurel, curvina, blanquillo y lenguado), importantes por sus volúmenes; recursos complementarios (escama, tiburones y rayas, invertebrados), se capturan de manera incidental o en menor cantidad (Cota-Nieto et al., 2015). Proveniente del monitoreo espacial (trackers), tenemos registrados 1,901 viajes de pesca: 151 de curvina, 1,171 de verdillo y 165 de lenguado. La información colectada se utiliza en los análisis espaciales tomando en cuenta únicamente los datos de capturas por lance. Se obtienen las coordenadas de estos lances y se hacen mapas de intensidad pesquera para cada especie objetivo, además de un mapa de productividad pesquera (figura 8). Del total de la zona pesquera para la comunidad de Punta Abreojos, $23 \%$ de las unidades espaciales (pixeles) se consideran las más productivas y se encuentran dentro de un límite de 10 $\mathrm{km}$ de la costa. Esto beneficia, en gran parte, a la dinámica pesquera, 


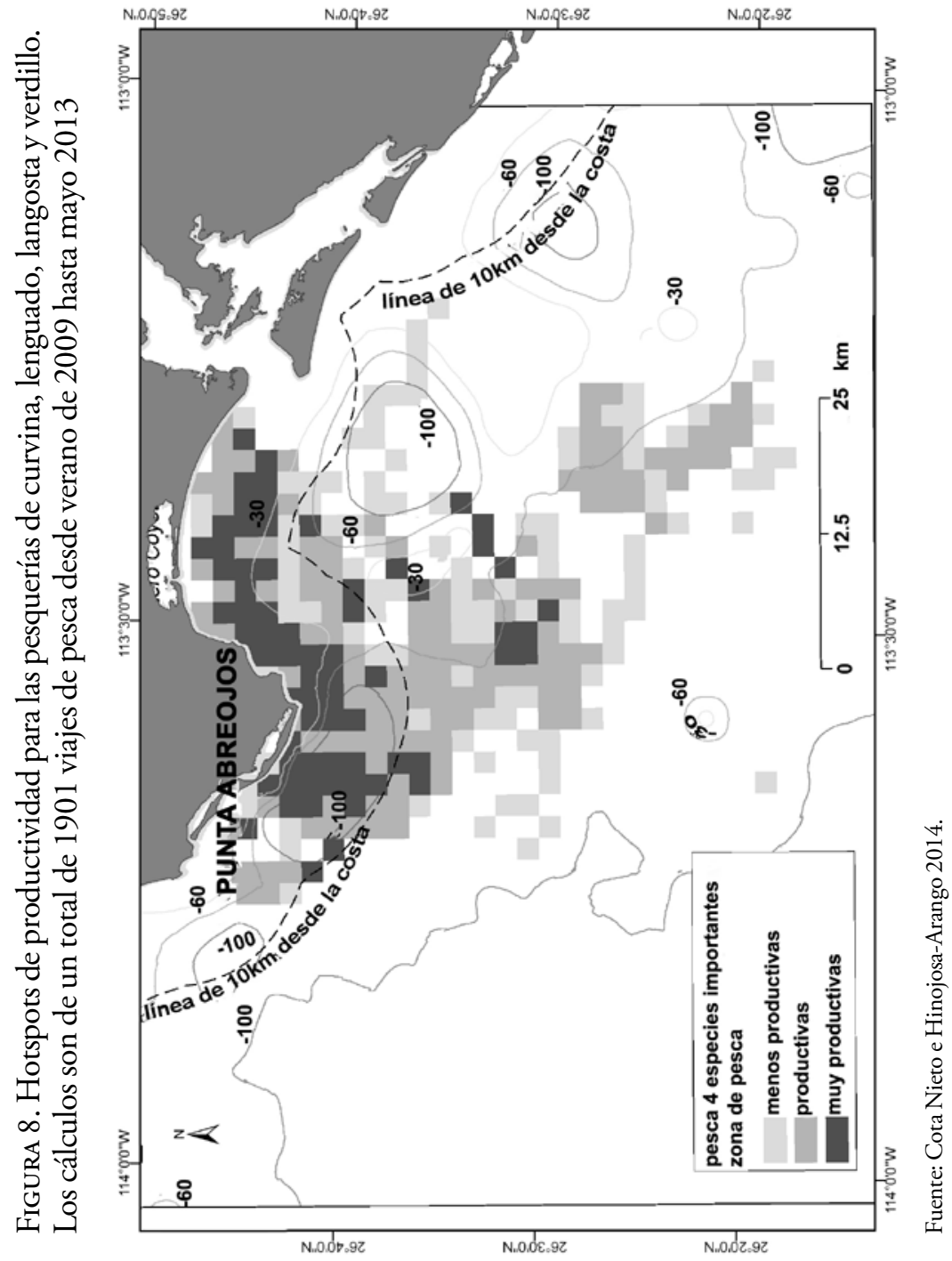


ya que mantiene los costos operativos (costo por viaje), riesgos, etcétera, en niveles bajos.

Las capturas de estos recursos se han mantenido estables dadas las medidas de manejo estrictas que existen (concesión, cuotas de captura, tallas mínimas de captura, ecocertificaciones internacionales). Los recursos objetivos y complementarios generan ganancias a los pescadores y a la Cooperativa durante los periodos de veda de los recursos denominados como culturales (langosta y abulón). La información nos ayudó a crear una línea base de ganancias directas para los pescadores, lo cual ayuda a la Cooperativa a administrar sus actividades pesqueras para garantizar una pesca responsable en el largo plazo. Es una manera de garantizar que la pesca sea redituable durante mucho tiempo, y permite a la Cooperativa modificar sus actividades $\mathrm{o}$ adaptarse a condiciones adversas.

\section{Complejo Lagunar Bahía Magdalena-Almejas}

En Bahía Magdalena-Almejas aplicamos el PCC para conocer la dinámica pesquera de la flota ribereña de las principales pesquerías (camarón, pierna, jaiba, jurel, meros y cabrillas, verdillo, estacuda, botete, huachinango, manta, vieja y tiburón). Es uno de los ecosistemas marinos de mayor biodiversidad, productividad e importancia económica en el estado de Baja California Sur, operan alrededor de 720 embarcaciones menores (Ojeda-Ruiz y Ramírez-Rodríguez 2012, 184-204). Los bosques de manglares, esteros, barras arenosas, zonas rocosas, islas y canales son hábitats de gran relevancia, ya que la región forma parte de un corredor biológico y circuito migratorio de organismos protegidos, como son las tortugas marinas, elefantes y lobos marinos, ballena gris, ballena azul y ballena jorobada (Marcín-Medina et al., 2014, 635-654) y avistamiento de aves, por lo que el complejo lagunar está en la mira del sector conservación. Se extiende por la costa oeste de Baja California Sur, se encuentra ubicado entre los municipios de La Paz y Comondú. Las comunidades de Puerto Adolfo López Mateos, Puerto San Carlos y Puerto Chale se ubican dentro del complejo lagunar. Tiene tres zonas geomorfológicamente distintas (Figura 9): Zona de Canales al noroeste, for- 
Figura 9. Ubicación geográfica del Complejo Lagunar Bahía Magdalena-Almejas

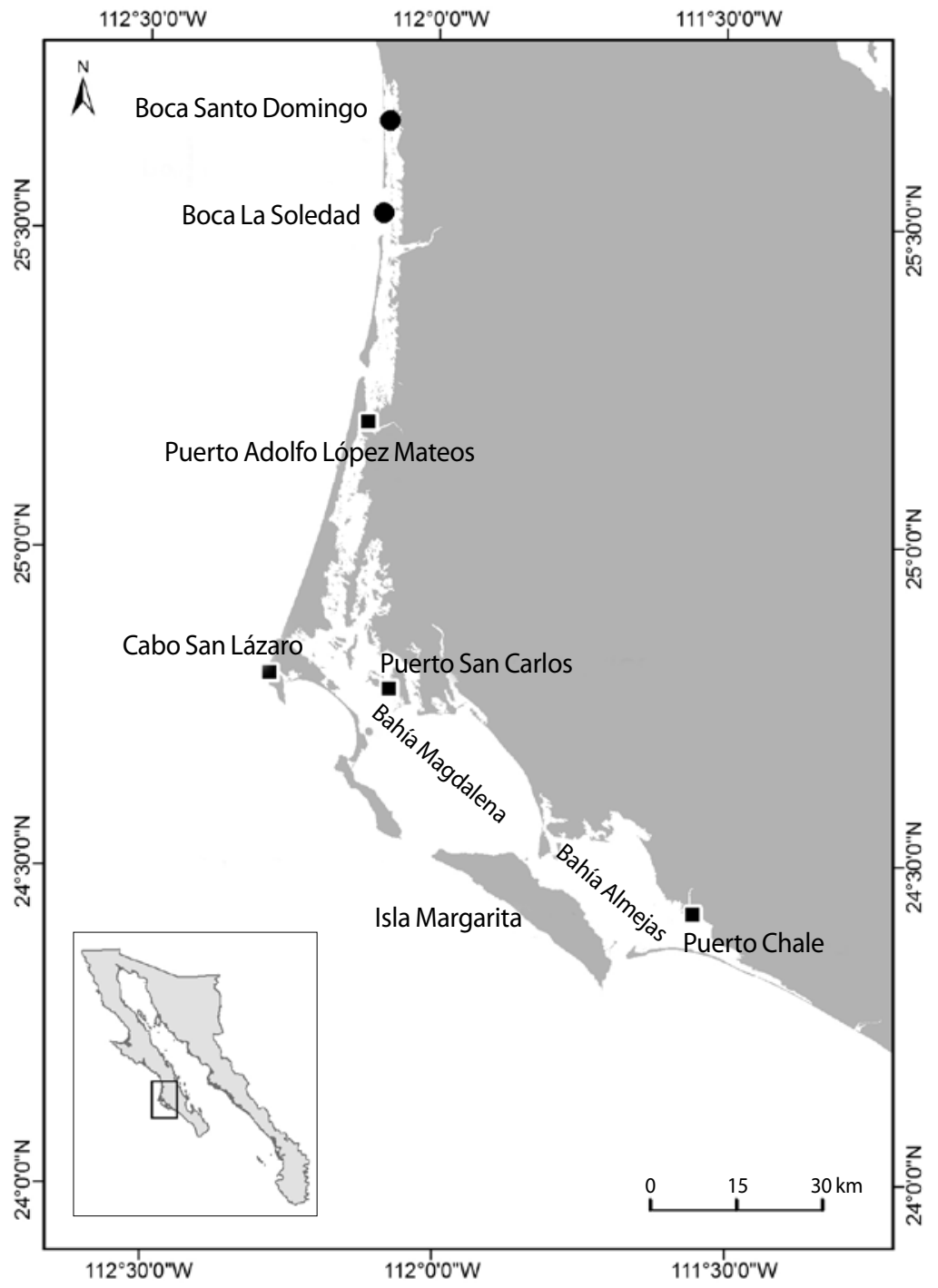


mada por una gran cantidad de esteros, lagunas y canales someros (profundidades entre 3.5-18 m); la parte central del complejo, Bahía Magdalena, se conecta con la plataforma continental a través de una boca formada entre las islas Magdalena y Margarita; y Bahía Almejas en la parte sureste, con una profundidad promedio de 8 metros, que se comunica con el océano Pacífico por un canal formado por las islas Margaritas y Creciente (Marcín-Medina et al., 2014, 635-654). Las zonas productivas del complejo lagunar presentan cierta regularidad de localización, siendo la porción central una de las más importantes para los moluscos bivalvos y camarón, mientras que la escama se puede obtener de los canales de manglares o en la parte externa de la bahía (Acosta-Velázquez y Vázquez-Lule 2009, 18).

Parte de Bahía Magdalena-Almejas forma parte del llamado Golfo de Ulloa; la costa de la región se desarrolla a lo largo de 348.9 $\mathrm{km}$, desde Punta Abreojos en su porción norte, hasta Cabo San Lázaro en su extremo sur (figura 10). Cuenta con siete cuerpos de aguas interiores (lagunas, esteros y humedales) que cubren una superficie de 94,882 hectáreas, de las cuales $63.7 \%$ representan a la porción del complejo lagunar de Bahía Magdalena y $29.4 \%$ a la laguna San Ignacio. Es un ecosistema de interés económico y científico, con gran importancia para el sostenimiento de recursos naturales y pesqueros. Esta región cuenta con 26 comunidades costeras con aproximadamente 8,000 habitantes (SAGARPA y CONAPESCA 2014, 61). Se explotan diversas especies de moluscos (abulón, almejas, caracol, pulpo); crustáceos (langosta, camarón, jaiba); tiburones, rayas y peces (escama). La pesca ribereña en la región es muy importante para la economía de las comunidades locales y para Baja California Sur, sin embargo, la región representa un reto para la sustentabilidad y pesca responsable, ya que existen problemas con permisos de pesca, la sobreexplotación de algunos recursos pesqueros y la mortandad de tortugas amarillas o caguamas, especie protegida por la NOM-059-SEMARNAT y considerada en peligro por la Lista Roja de la UICN y Endangered Species Act, lo que amenaza el desarrollo de la región (Ramírez Rodríguez et al., 2010, 66).

Empezamos a implementar el PCC en la región en 2012, generando información espacial de las principales pesquerías: almeja ge- 
FigurA io. Localización del Golfo de Ulloa (GU) en la costa occidental de Baja California Sur

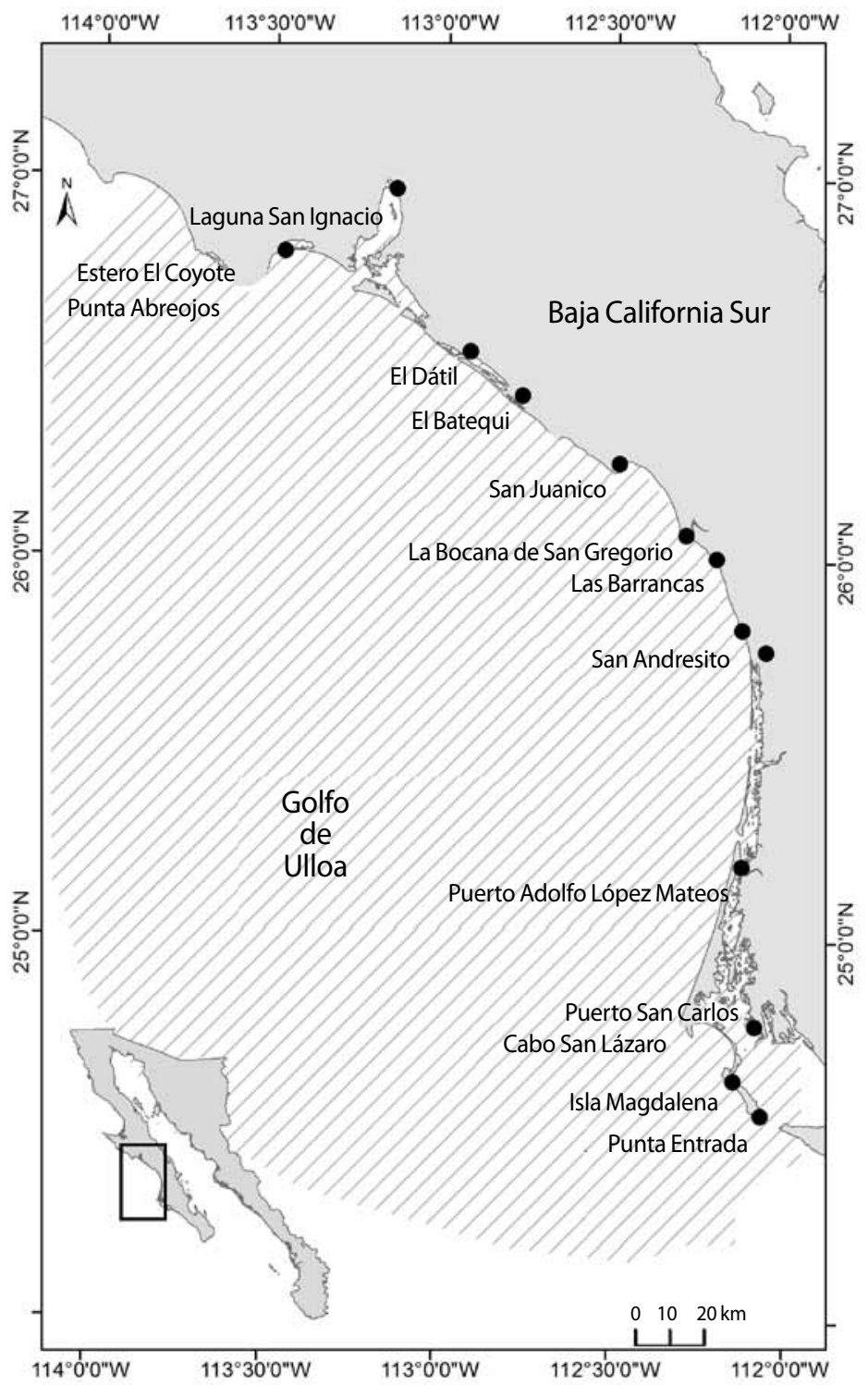


nerosa, camarón, jaiba y escama (18 especies); durante cuatro años trabajamos únicamente con las comunidades de Puerto San Carlos y Puerto Chale. Nuestra base de datos cuenta con 2,379 registros, que corresponden a 1,736 viajes de pesca, se han identificado más de 2,000 puntos de pesca, con lo que determinamos la distribución de la actividad pesquera y la asociamos a hábitats particulares (CotaNieto et al., 2016). Utilizamos las descripciones de hábitats marinos hechas por Rioja-Nieto y colaboradores (2013) y la información GIS de bosques de manglar de la Comisión Nacional para el Conocimiento y Uso de la Biodiversidad (Conabio) para mostrar los distintos hábitats en Bahía Magdalena-Almejas. Además, aplicamos 100 entrevistas a pescadores para validar información pesquera generada desde el 2012 con los trackers, y calculamos la jornada y la distancia promedio de los viajes de pesca para cada recurso pesquero. Las pesquerías ribereńas, en conjunto, generaron 3.05 millones de pesos de 2012 a febrero de 2016.

Identificamos cinco tipos de hábitats asociados a las pesquerías de esta región: 1) Manglar; 2) Macroalgas; 3) Pastos Marinos; 4) Zonas Arenosas; 5) Zonas Profundas. La jornada más larga y la más corta que identificamos se refieren a la pesquería de escama: $192 \mathrm{~km}$ y 14 horas, $3.4 \mathrm{~km}$ y 5 horas respectivamente. El camarón se captura en zonas cercanas a los manglares, en las praderas de pastos marinos y en zonas arenosas que van desde $6 \mathrm{~m}$ hasta $50 \mathrm{~m}$ de profundidad (Cota-Nieto et al., 2016). Por otra parte, con los registros pesqueros de captura de Conapesca para el periodo 2001-2013 se analizaron las tendencias de captura de las tres oficinas de Bahía Magdalena-Almejas (Puerto Adolfo López Mateos, Puerto San Carlos y Ciudad Constitución) y se analizaron las capturas del resto de las oficinas de Baja California Sur para dimensionar el valor pesquero y económico de una zona. Encontramos que entre 2001-2015, en Bahía Magdalena-Almejas, la pesca ribereña produjo 242,000 toneladas (22.5\% de las capturas totales) del total de las capturas en Baja California Sur. En cuanto a valoración económica se generaron 2,807 millones de pesos, que corresponden a $64 \%$ del ingreso económico total de la región (Cota-Nieto et al., 2015). 
Las comunidades conocen los retos de sustentabilidad en la manera en que aprovechan los recursos pesqueros y las implicaciones directas para su sustento económico. Sin embargo, tal parece que la historia de conflicto entre el sector conservación y pesquero que ocurrió en el Alto Golfo comienza a ser replicado en esta región. El sector conservación asegura que la principal causa de mortandad de tortuga es debido a la captura incidental en redes y ha presionado al gobierno para implementar medidas de protección para los quelonios (CEMDA y Defenders of Wildlife 2013), el sector pesquero asegura que no es la pesca ribereńa la causante de esta problemática (BCS Noticias 2016). En un primer intento por reducir la mortandad de tortugas en el Golfo de Ulloa, en 2010, el Subcomité de Pesca y Recursos Marinos del Municipio de Comondú integró una mesa técnica para la elaboración de un plan de manejo de las pesquerías de escama en la región, haciendo énfasis en Puerto Adolfo López Mateos (Ramírez Rodríguez et al., 2010, 66). Esta mesa técnica contemplaba un estudio para mejorar las condiciones de aprovechamiento de los recursos pesqueros; impactar positivamente la economía de los pescadores y sus comunidades; y contribuir a la protección de la tortuga caguama o amarilla. Entre las estrategias que el gobierno mexicano implementó para asegurar la protección de la tortuga amarilla o caguama está la creación de un refugio pesquero, dentro del cual todas las actividades extractivas estarán sujetas a medidas de verificación, inspección y vigilancia (DOF 2016). Pero esto no fue suficiente y, en 2015, la Administración Nacional Oceánica y Atmosférica de Estados Unidos (NOAA por sus siglas en inglés) certificó negativamente a México, en virtud de la Ley de Protección de la Moratoria de Pesca con Redes de Enmalle en Alta Mar, por no tener un programa eficiente para reducir la captura incidental de tortugas amarillas o caguamas comparable en eficacia al de Estados Unidos (NOAA 2015, 107) (La Jornada 2015), lo que podría desencadenar un embargo comercial pesquero en los productos provenientes del Golfo de Ulloa, o medidas más drásticas como posibles restricciones de importación de productos pesqueros por parte de Estados Unidos (Henderschedt 2015, 17). En un esfuerzo de las autoridades mexicanas por evitar un embargo y deter- 
Figura i i. Vértices de la Zona de Refugio Pesquero

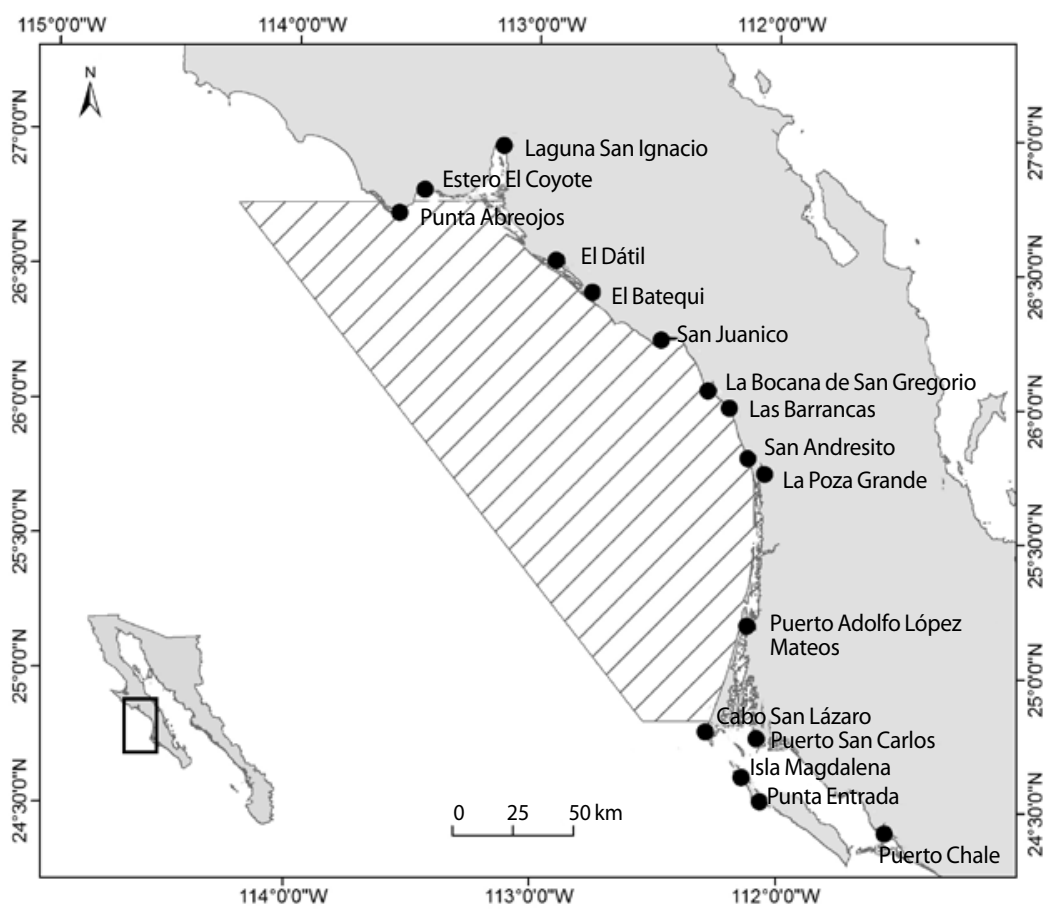

Fuente: DOF 2016.

minar la causa principal de muertes de tortugas, en el segundo trimestre del 2016, se determinó una veda total de cuatro meses en el Golfo de Ulloa para las pesquerías de escama y tiburón ${ }^{7}$ (figura 11) excluyendo las pesquerías de abulón, langosta, almejas, caracoles, pulpo y pepino de mar, ya que no representan amenaza para la tortuga (DOF 2016). Esta veda afectó a más de mil pescadores, a los cuales se les dio una compensación económica con base en la producción promedio de los últimos cinco años; el total de apoyo fue de 70 millones de pesos durante el lapso que dure la temporada de

7 Suspensión de las actividades pesqueras con embarcaciones mayores y menores hasta el 30 de septiembre del 2016. 
veda (sAGARPA 2016). El 1 de septiembre de 2016, NOAA decidió cambiar el dictamen sobre la certificación de las pesquerías en México, gracias a las acciones que tomaron las comunidades y autoridades para reducir la pesca incidental de tortugas marinas en el Golfo de Ulloa. Esta certificación se dio después de la publicación hecha por México de normas reforzadas (incluyendo el periodo de veda), y de una reunión, en julio de 2016, entre el presidente de Estados Unidos y el presidente mexicano. En esa reunión, se reafirmó el compromiso del gobierno mexicano de continuar manteniendo las medidas de protección a largo plazo para las tortugas caguama.

Ante esta situación los pescadores de Puerto Adolfo López Mateos se acercaron al PMGC en junio de 2016 y propusieron integrarse al PCC, después de asistir a distintas reuniones donde expusimos el trabajo que hemos realizado. Los pescadores han visto la semejanza de su situación con lo ocurrido en el Alto Golfo y comprenden los beneficios que resultan de involucrarse en un programa como el nuestro, donde podrán participar completamente en el proceso de generación de información. La actual situación que vive el Golfo de Ulloa ha sido trascendental para la aceptación del programa; el sector pesquero de esta zona, particularmente Puerto Adolfo López Mateos, está viviendo uno de los momentos de mayor presión, pero los pescadores están decididos a trabajar de manera colaborativa para diseñar estrategias de manejo que se adecuen a las necesidades y objetivos de conservación establecidos para la región.

\section{Conclusión}

A pesar de ser una de las actividades más importantes del Golfo de California y base de la economía de las comunidades costeras, el panorama de las comunidades pesqueras en el noroeste de México no es el más esperanzador. Los pescadores artesanales deben enfrentar distintos retos, desde la falta de infraestructura, contaminación, deterioro ambiental, cambio climático y sobrepesca para cumplir el objetivo de sustentabilidad y garantizar la permanencia de la actividad.

Los eventos de los últimos años han resaltado la inclinación del gobierno a privilegiar al sector conservación y minimizar la impor- 
tancia del aspecto social, lo que resulta en acciones radicales de conservación, con un efecto negativo para los pescadores y todos los que dependen de la actividad pesquera. Estas medidas han dejado fuera a sectores importantes de la población, con ellas podría decirse que se benefician únicamente el sector conservación y la autoridad, pero no necesariamente son de beneficio público. Por eso la necesidad de avanzar a una idea de lo público, basándonos en la identidad local, e incentivar el sentido de apropiación y pertenencia para garantizar que las medidas de manejo se apliquen adecuadamente.

Las comunidades deben ser incluidas en los esfuerzos de investigación, somos conscientes de las necesidades de la actividad pesquera y comprendemos la importancia de considerar a todos los actores involucrados para entender la relación entre la actividad pesquera y los recursos para lograr ecosistemas saludables. Cuando se combinan herramientas y metodologías que generan información científica e incorporan estrategias de comunicación, es posible llegar a acuerdos a partir de un diálogo abierto y honesto, que permite una negociación cuyo resultado refleje las necesidades de todos los involucrados. No es fácil integrar al público con la ciencia, las distintas agendas de gobierno, sector conservación y pesquero han perjudicado la relación entre la ciencia y la sociedad.

Metodologías como el PCC han permitido establecer una relación más estrecha entre científicos y usuarios, lo cual tiene un impacto positivo en el cumplimiento de las metas de conservación que se han planteado en las comunidades donde el Programa se ha implementado. El pCc tiene un valor incalculable para la investigación y el crecimiento sostenible de la región, hemos demostrado que la información generada es objetiva y libre de alguna agenda específica. Compartir datos e información con actores locales y regionales es una manera de asegurar el uso eficaz de estos datos en el desarrollo de políticas y para el manejo de recursos. Para llegar a medidas de manejo pesquero efectivas se necesita trabajar de manera colaborativa con todos los grupos de interés, ya sean universidades, organizaciones regionales y comunidades locales para desarrollar capacidades y participar en foros compartiendo conocimientos y experiencias. 
Bibliografía

Aburto-Oropeza, Octavio, Catalina López-Sagástegui, Marcia Moreno-BÁez, Ismael Mascareñas-Osorio, Victoria JiméNEZ Esquivel, Andrew Johnson y Brad Erisman. 2016. "Endangered Species, Ecosystem Integrity and Human Livelihoods". Conservation Letters 8. doi:10.1111/conl.12317.

Acosta-VelázQuez, Joanna y Alma VázQuez-Lule. 2009. Caracterización del sitio de manglar Bahia Magdalena. Sitios de Manglar con relevancia biológica y con necesidades de rehabilitación ecológica. México: Comisión Nacional para el Conocimiento y Uso de la Biodiversidad (CONABIo), 18.

Amezcua, Felipe. 2011. "La ciencia pesquera, la conservación de la biodiversidad y el desarrollo sustentable”. La Jornada Ecológica. 28 de Noviembre. http:/www.jornada.unam.mx/2011/11/28/ eco-c.html (Fecha de consulta: 12 de septiembre de 2016).

Arreguín Sánchez, Francisco. 2006. "Pesquerías de México". En Pesca, acuacultura e investigación en México. Comisión de Pesca y Centro de Estudios para el Desarrollo Rural Sustentable, 384. México: Cámara de Diputados.

BCS Noticias. 2016. "Pescadores no causan mortandad de tortugas en Golfo de Ulloa: Fonmar; siguen los decesos”. BCS Noticias. Agosto 5. http://www.bcsnoticias.mx/pescadores-no-causanmortandad-de-tortugas-en-golfo-de-ulloa-fonmar-siguen-losdecesos/

Bravo-Olivas, Myrna Leticia, Rosa María Chávez-Dagostino, Elaine Espino-Barr y Rocío Jazmín Rosas-Puga. 2014. "Huella de la pesca ribereña”. En Temas sobre Investigaciones Costeras, ed. Juan Luis Cifuentes Lemus y Fabio Germán Cupul Magaña, 321. Guadalajara: Universidad de Guadalajara.

Brusca, Richard, Saúl Álvarez-Borrego, Philip Hastings y Lloyd T. Findley. 2017. "Colorado River Flow and Biological Productivity in the Northern Gulf of California, México". Earth-Science Reviews, vol. 164 (enero): 1-30. doi:http://dx.doi. org/10.1016/j.earscirev.2016.10.012

CEMDA y Defenders of Wildlife. 2013. "Piden ONGs al gobierno 
detener alta mortandad de tortuga caguama”. Centro Mexicano de Derecho Ambiental, 19 de junio. http://www.cemda.org.mx/ piden-ongs-al-gobierno-detener-alta-mortandad-de-tortuga-caguamal

Cortés, Rocío Areli, German Ponce Díaz y Manuel Villa. 2006. "El sector pesquero en Baja California Sur: un enfoque de insumo-producto". Región y Sociedad 18(35): 107-129.

Cota-Nieto, Juan José. 2012. Punta Abreojos, sitio fundamental en el manejo de los recursos naturales. Reporte de Actividades. México: Fondo Mexicano para la Conservación de la Naturaleza AC.

Cota-Nieto, Juan José, Brad Erisman, Marcia Moreno-Báez, Gustavo Hinojosa-Arango y Octavio Aburto-Oropeza. 2015. "La pesca, motor del desarrollo en Punta Abeojos, BCS". DataMares. doi:http://dx.doi.org/10.13022/M31S3R

Cota-Nieto, Juan José, Victoria JimÉnez Esquivel y Ismael MasCAREŃAs-Osorio. 2016. "Bahía Magdalena: Habitat Diversity Sustains Fisheries". DataMares. http://dx.doi.org/10.13022/ M3HP4F (Fecha de consulta: 27 de septiembre de 2016).

Cudney-Bueno, Roger Sean y Peggy Turk-Boyer. 1998. Pescando entre mareas del Alto Golfo de California: Una guía sobre la pesca artesanal, su gente y sus propuestas de manejo. Puerto Peñasco: Centro Intercultural de Estudios de Desierto y Océanos.

Díaz-Uribe, Juan Gabriel, Víctor Manuel Valdez-Ornelas, Gustavo D. Danemann, Esteban Torreblanca-Ramírez, Alejandro Castillo-López y Miguel Ángel Cisneros-Mata. 2013. "Regionalización de la pesca ribereña en el noroeste de México como base práctica para su manejo". Ciencia Pesquera 21(1): 41-54.

DOF. 2016."ACUERDO por el que establece la zona de refugio pesquero y nuevas medidas para reducir la posible interacción de la pesca con tortugas marinas en la costa occidental de Baja California Sur". Diario Oficial de la Federación, junio 23.

2015. "ACUERDO por el que se suspende temporalmente la pesca comercial mediante el uso de redes de enmalle, cimbras y/o palangres operadas con embarcaciones menores, en el Norte del Golfo de California”. Diario Oficial de la Federación, abril 10. EDF. 2015. María Curvina. "Biologia, manejo pesquero y procesos 
de producción", 1-10. http://www.edfclimatecorps.net/sites/default/files/content/bookletmariacurvinabajares.pdf

Erisman, Brad, Ismael Mascareñas-Osorio, Catalina López-SáGASTEGUI, Marcia Moreno-BáeZ, Victoria JimÉneZ Esquivel y Octavio Aburto-Oropeza. 2015. "A Comparison of Fishing Activities between Two Coastal Communities Within a Biosphere Reserve in the Upper Gulf of California”. Fisheries Research (164): 254-265.

Erisman, Brad, Octavio Aburto-Oropeza, Charlotte GonZalez - Abraham, Ismael Mascareñas-Osorio, Marcia MorenoBáez y Philip A. Hastings. 2012. "Spatio-Temporal Dynamics of a Fish Spawning Aggregation and Its Fishery in the Gulf of California". Scientific Reports: 1-11.

FAO. 2010. Estudio social de la pesca en México: diagnóstico sobre la problemática social de los pescadores, su entorno y su visión sobre las posibles soluciones a los problemas que afectan la pesca. Roma: Organización de las Naciones Unidas para la Agricultura y la Alimentación, 30.

HeNDERSCHEDT, John. 2015. International Affairs and Seafood Inspection Update. ICCAT Advisory Committe, National Oceanic and Atmospheric Administration, 17.

Hinojosa, Osvel y Yamilett Carrillo. 2010. "La cuencua binacional del río Colorado". En Las cuencas hidrográficas de México, ed. Instituto Nacional de Ecología, 180-187. México: Secretaría de Medio Ambiente y Recursos Naturales.

INE. 2004. Estado del medio ambiente: Zonas marinas y costeras. México: Instituto Nacional de Ecología, 94-117.

. 2000. Indicadores para la evaluacón del desempeño ambiental: Recursos pesqueros. México: Instituto Nacional de Ecología.

JimÉneZ Esquivel, Victoria e Ismael MasCareñas-Osorio. 2015. "The Lunar Cycle and the Fisheries of the Upper Gulf of California". DataMares. doi:http://dx.doi.org/10.13022/M3X30S Johnson, Andrew, Catalina López-Sagástegui, Arturo RamírezValdez, Octavio Aburto-Oropeza, Ismael Mascareñas-Osorio y Alfredo Girón-Nava. 2015. "Kilos and Pesos". DataMares. Interative Resources. http://dx.doi.org/10.13022/M3KS3Q 
La Jornada. 2015. "Lamenta México certificación negativa de EU por captura de caguamas". 16 de agosto de 21.

LóPEZ-SÁGASTEGUI, Catalina. 2014. Ciencia, pesca, conservación y manejo de recursos. http://gulfprogram.ucsd.edu/blog/climatechange/ciencia-pesca-conservacion-y-manejo-de-recursos/ (Fecha de consulta: 10 de septiembre de 2016).

López-Sagástegui, Catalina, Alejandro Robles y Mara HérnanDEZ. 2010. Dialogo y Construcción de acuerdos en el Alto Golfo de California: El caso de Alto Golfo Sustentable. Reporte Final. México: Centro de Colaboración Civica.

López-SÁgastegui, Catalina y Octavio Aburto-Oropeza. 2016. "La nueva ciencia busca conservar y aprovechar los recursos". $L a$ Jornada Ecológica, febrero. http://www.jornada.unam. $\mathrm{mx} / 2016 / 02 / 01 /$ eco-d.html (Fecha de consulta: 12 de septiembre de 2016).

López-SÁGastegui, Catalina, Ismael Mascareñas-Osorio, Victoria JimÉNEZ Esquivel, Alfredo Girón-NaVA, Andrew JoHnson y Octavio Aburto-Oropeza. 2016. "Valor de la actividad pesquera en el Alto Golfo de California". DataMares. doi:http:// doi.org/10.13022/M34G6Q

López-Sagástegui, Catalina, Octavio Aburto-Oropeza, Marcia Moreno Báez, Ismael Mascareñas Osorio y Gustavo HinojoSA Arango. 2014. "Ciencia ciudadana en el Alto Golfo de California”. Biodiversitas (CONABIO) (116) (septiembre-octubre): 1-6. Marcín-Medina, Rocío, Gustavo Hinojosa-Arango, Jorge López-Calderón, Alejandro Gómez-Gallardo, Eduardo NÁjera-Hillman y Rafael Riosmena-Rodríguez. 2014. "El impacto ambiental de proyectos portuarios turísticos en bahía Magdalena, Baja California Sur, México". En Pacífico Mexicano. Contaminación e impacto ambiental: diagnóstico y tendencias, ed. A.V. Botello, F. Páez-Osuna, L. Mendez-Rodríguez, M. Betancourt-Lozano, S. Álvarez-Borrego y R. Lara-Lara, 635-654. Mazatlán: UAC/UnAM/ ICMYL/CIAD Mazatlán/CIBNOR/CICESE.

Moreno-Báez, Marcia, Ismael Mascareñas-Osorio, Juan José Cota Nieto, Victoria JimÉnez Esquivel, Catalina López-SÁgastegui y Octavio Aburto-Oropeza. 2014. Protocolo para la 
Colecta de Información Espacio-temporal y Pesquera. Protocolo. Scripps Institution of Oceanography-Centro para la Biodiversidad Marina y la Conservación AC.

NOAA. 2015. Improving International Fisheries Management. National Oceanic and Atmospheric Administration, 107.

Ojeda-Ruiz, Miguel Ángel y Mauricio Ramírez-Rodríguez. 2012. "Interacciones de pesquerías ribereñas en Bahía Magdalena-Almejas, Baja California Sur”. Región y Sociedad 24 (53): 189-204. http://www.scielo.org.mx/scielo.php?script=sci_ arttext\&pid=S1870-39252012000100006\&lng=es\&nrm=iso

Orozco, Maria de Lourdes. 1998. "Pobreza y explotación de recursos pesqueros en el Alto Golfo de California". Comercio Exterior 48(12): 1002-1011.

Ortiz, Rafael, Ismael Mascareñas-Osorio, Martha Román y Julián CAstro. 2016. "Biological and Fisheries Monitoring of the Gulf Curvina in the Upper Gulf of California". DataMares. doi:http://doi.org/10.13022/M38590.

Pérez-Valencia, Sergio Alejandro, Marisela Gorostieta-Monjaraz, Veronica Castañeda-Fernández de Lara, Elia Ines Polanco-Mizquez, Alejandro Rodríguez-Uceda, Omar Onan-Quintero, Rene Loaiza-Villanueva, Peggy Turk-BoYer y Caroline Downton-Hoffmann. 2015. MIA-R para la Pesca Ribereña Responsable en la Reserva de la Biosfera Alto Golfo de California y Delta del Rio Colorado: Alto Golfo de California. MIA. Puerto Peñasco: Centro Intercultural de Estudios de Desiertos y Océanos AC, 234.

Ramírez Rodríguez, Mauricio, Gustavo De la Cruz Agüero, Elvia Aída Marín Monroy, Miguel Ángel Ojeda de la PeÑa y Germán Ponce Díaz. 2010. Estudio sobre la caracterización socioeconómica y pesquera del área del Golfo de Ulloa, Baja California Sur. Reporte Final. La Paz: Centro Interdisciplinario de Ciencias Marinas del Instituto Politécnico Nacional, 66.

Rodríguez-Valencia, José Alejandro y Miguel Angel CisnerosMARA. 2006. Captura incidental de las flotas pesqueras ribereñas del Pacífico Mexicano. Reporte Técnico del Programa Golfo de California de wwwF-México, México: Comisión de Cooperación 
Ambiental de América del Norte, 127. http://d2ouvy59p0dg6k. cloudfront.net/downloads/rep_06_captura_incidental_flotas_riberena_pacificomx.pdf

SAGARPA. 2016. "Comunicado de Prensa. Hoy inicia veda en Golfo de Ulloa”. La Paz: Secretaría de Agricultura, Ganadería, Desarrollo Rural, Pesca y Alimentación, 2.

SAGARPA y CONAPESCA. 2014. "Programa integral de ordenamiento pesquero en el Golfo de Ulloa, Baja California Sur”. https:/documentop.com/programa-integral-de-ordenamientopesquero-en-el-golfo-de-cofemer_59ff7cf61723dd5364c2eba9. html

Salas, Silvia, Ratana Chuenpagdee, Juan Carlos Seijo y Anthony Charles. 2007. "Challenges in the Assessment and Management of Small-Scale Fisheries in Latin America and the Caribbean". Fisheries Research 87(1): 5-16.

Santos, Milton. 2000. La naturaleza del espacio: Técnica y Tiempo: Razón y Emoción. Barcelona: Editorial Ariel, 92.

Vega-VelázQuez, Armando. 2004. Administración de la pesquería de langosta del Pacifico en Baja California Sur. La Paz: SAgARPa/ INAPESCA, Centro Regional de Investigaciones Pesqueras La Paz. VIDAL, Omar. 1995. "Population Biology and Incidental Mortality of the Vaquita, Phocoena sinus". International Whaling Commission (16): 247-272.

Wilkinson, Tara, Ed Wiken, Juan Bezaury Creel, Thomas Hourigan, Tundi Agardy, Hans Herrmann, Lisa Janishevski, Christopher Madden, Lance Morgan y Moreno Padilla. 2009. Ecorregiones marinas de Ámerica del Norte. Informe Final, Montreal: Comision para la Cooperación Ambiental, 200. http:// www3.cec.org/islandora/es/item/3256-marine-ecoregions-northamerica-es.pdf (Fecha de consulta: 22 de septiembre de 2016). 